\title{
Editorial Expression of Concern: Specialization increases in a frugivorous bird-plant network from an isolated montane forest remnant
}

\author{
Galo Buitrón-Jurado ${ }^{1} \cdot$ Virginia Sanz ${ }^{1}$
}

Published online: 5 August 2021

(c) Akadémiai Kiadó Zrt. 2021

\section{Editorial Expression of Concern re: Community Ecology https://doi.org/10.1007/s42974-020-00010-x}

The Editor-in-Chief is issuing this editorial Expression of Concern to make readers aware that there is an unresolved dispute between the authors of this article (Buitrón-Jurado and Sanz 2020).

Co-author Virginia Sanz states that although she contributed to the research presented in the article and to the earlier drafts of the manuscript, she was not aware of the submission to Community Ecology, did not agree with the conclusions of the article, and did not authorize the version of the article published in Community Ecology.

An investigation was conducted in accordance to the Core Practices of the Committee on Publication Ethics (COPE) of which the journal is a member.
The Venezuelan Institute for Scientific Research (IVIC) confirmed that Galo Buitrón-Jurado was a student of Virginia Sanz and, in line with institutional guidelines, should have collaborated with Dr. Sanz in preparing this article.

The Editor-in-Chief considered explanations from both authors regarding potential errors in the article and concluded that a correction is not needed.

Galo Buitrón-Jurado agrees to this editorial expression of concern.

Virginia Sanz does not agree to this editorial expression of concern.

\section{Reference}

Buitrón-Jurado, G., \& Sanz, V. (2020). Specialization increases in a frugivorous bird-plant network from an isolated montane forest remnant. Community Ecology. https://doi.org/10.1007/ s42974-020-00010-x
The original article can be found online at https://doi.org/10.1007/ s42974-020-00010-x.

Galo Buitrón-Jurado galobuitronj@yahoo.es

1 Laboratorio de Biología de Organismos, Centro de Ecología, Instituto Venezolano de Investigaciones Científicas, Km 11 Carretera Panamericana, Apartado 2032, Caracas 1020-A, Miranda, Venezuela 